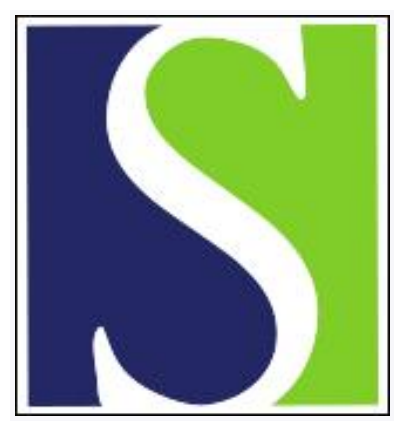

Scand J Work Environ Health 1993;19(5):346-351

https://doi.org/10.5271/sjweh.1464

Issue date: 01 Oct 1993

Association between asbestos-related pleural plaques and resting hyperventilation.

by Dujic Z, Eterovic D, Tocilj J

Affiliation: Department of Physiology, Zagreb University School of Medicine in Split, Croatia.

This article in PubMed: www.ncbi.nlm.nih.gov/pubmed/8296184

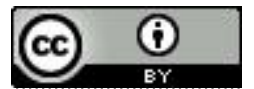




\title{
Association between asbestos-related pleural plaques and resting hyperventilation
}

\author{
by Željko Dujić MD, ${ }^{1}$ Davor Eterović, PhD, ${ }^{2}$ Jadranka Tocilj, $\mathrm{MD}^{3}$
}

\begin{abstract}
DUJIĆ Ž, ETEROVIĆ D, TOCILJ J. Association between asbestos-related pleural plaques and resting hyperventilation. Scand $J$ Work Environ Health 1993;19:346-51. This study reports an association between pleural plaques and resting hyperventilation in a group of workers exposed to asbestos. Information on exposure level, pack-years of cigarette smoking, chest radiographs, ventilation parameters, single-breath diffusing lung capacity, and arterial gases were obtained for 344 workers. After the exclusion of 37 workers for isolated parenchymal fibrosis, combined pleuroparenchymal fibrosis, or diffuse pleural thickening, 55 subjects with isolated pleural plaques were evaluated against 252 no-plaque workers. A quantitative pleural score revealed mild pleural disease. Forty-four workers with plaques $(80 \%)$ had hypocapnia induced by resting hyperventilation. The quantitative pleural score correlated significantly with the partial pressure of carbon dioxide in arterial blood (correlation coefficient $=-0.7$ ). A decrement in forced vital capacity was associated with plaques, whether controlled for age, smoking, and exposure or not. It was concluded that the resting hyperventilation observed in some asbestos-exposed subjects is related to the presence of mild pleural plaques and a restrictive disorder.
\end{abstract}

Key terms: dyspnea, occupational disease, pulmonary function.

Long-term asbestos exposure can cause fibrosis of the lung parenchyma or the pleura. Two pleural manifestations are pleural plaques and, less frequently, diffuse pleural thickening. The functional impairment caused by the latter has been thoroughly investigated (1). As for pleural plaques, Oliver et al $(2,3)$ reported their association with restrictive functional findings. This issue has been recently reviewed by Schwartz (4).

Our study concerns the significant prevalence of resting hyperventilation and restrictive disorder in asbestos-exposed subjects with mild pleural plaques. Resting hyperventilation has previously been observed only in advanced parenchymal and pleural asbestosis (5), due to diffusion impairment, and in patients chronic obstructive pulmonary disease (6), due to ventilation or perfusion impairment.

\section{Subjects and methods}

We undertook a cross-sectional study of 344 workers from the asbestos-cement factory in the industrial zone of Split, Croatia. Two-hundred and eightyfour of the workers were current employees, and they

Department of Physiology, Zagreb University School of Medicine in Split, Split, Croatia.

2 Department of Nuclear Medicine, Clinical Hospital Split, Split, Croatia.

3 Pulmonary Division, Clinical Hospital Split, Split, Croatia.

Reprint requests to: Dr Z̆ Dujić, Department of Physiology, Zagreb University School of Medicine in Split, Poljana Kneza Trpimira 1, 58000 Split, Croatia. amounted to $92 \%$ of all employees at the time of the study. The remaining 58 were retired workers, out of the 112 available from the retired work force. Attention was focused on 55 subjects $(16 \%)$ with isolated pleural plaques. Therefore, to eliminate potential confounders, we excluded 16 subjects $(4.7 \%)$ with isolated parenchymal radiological changes (profusion score $\leq 1 / 1$ according to the classification of the International Labour Office), 17 subjects (4.9\%) with combined pleuroparenchymal disease, and four subjects $(1.1 \%)$ with diffuse pleural thickening from the analysis. Thus 55 workers with isolated pleural plaques were analyzed against 252 fellow workers without plaques. The participants gave their occupational and medical histories and underwent physical examinations, chest radiographs, spirometry, and other selected tests. The study was approved by the Ethical Committee of the Hospital, and informed consent was obtained from all of the subjects.

Asbestos exposure was mainly to chrysotile, but about $12 \%$ of the exposure was to crocidolite, also used during the 1950 s up to 1964 . The factory products contained $84-86 \%$ cement and the rest was asbestos. Asbestos exposure data were available for the last 30 years. The exposures were assessed for each workplace on an annual basis. Dust particles were collected with an aspiration pump provided with filters of thin porous membranes of cellulose esters and counted by phase contrast microscopy, as the number of fibers greater than $5 \mu \mathrm{m}$ in length per milliliter. The cumulative exposure to asbestos in fiber-years for an individual was obtained as the concentrationweighted sum of exposures throughout the employment period, except for the 1950s. The exposure level 
for the $1950 \mathrm{~s}$ was taken to be 3 fibers $\cdot \mathrm{ml}^{-1}$. Roughly, the average concentrations were about 3 fibers $\cdot \mathrm{ml}^{-1}$ in the $1960 \mathrm{~s}, 2$ fibers $\cdot \mathrm{ml}^{-1}$ in the $1970 \mathrm{~s}$, and 1 fiber $\cdot \mathrm{ml}^{-1}$ in the $1980 \mathrm{~s}$. The factory was closed in 1989. Smoking and respiratory histories were taken as proposed by Ferris (7). A standardized questionnaire on respiratory symptoms was carried out by a trained chest physician. Dyspnea was evaluated only as a dichotomous variable, since a morereliable related parameter, partial pressure of carbon dioxide in arterial blood $\left(\mathrm{Pa}_{\mathrm{CO} 2}\right)$, was being measured.

The anthropometric characteristics, smoking habits, and exposure level of the workers are shown in table 1 according to the presence or absence of pleural plaques. The mean fiber-years was 32.7 (range $2-78$ ), and $41.9 \%$ were current smokers with mean pack-years of 31.4 (range $3-65$ ). The mean pleural score was 13.6 (range $4-51$ ). The group with plaques was significantly older and more heavily exposed, included a larger proportion of smokers, and had a greater mean of pack-years of cigarette smoking.

Standard posteroanterior radiographs at full inspiration were taken and read independently by two radiologists trained in the system of the International Labour Office (ILO) for classifying radiographs (8), without knowledge of the epidemiologic, clinical, and lung function data. Their average ILO score was adopted. Pleural plaques were defined when a plaque-like thickening at the lung pleura interface along the lateral thorax or either hemidiaphragm was $2 \mathrm{~mm}$ or more. Quantitative pleural scores were obtained according to Oliver et al (2).

Forced vital capacity (FVC), forced expiratory volume in $1 \mathrm{~s}\left(\mathrm{FEV}_{1.0}\right)$, the FEV\% $\left[\left(100 \cdot \mathrm{FEV}_{1.0}\right) /\right.$ FVC], and the maximal expiratory flow rates at 25 and $75 \%$ of the FVC ( $\mathrm{FEF}_{25}$ 75\%) were measured with a spirometer (Mijnhardt VICATEST ${ }^{\circledR}$, The Netherlands) using standard criteria of the American Thoracic Society (9). The largest value of three acceptable maneuvers was used. Predicted values were obtained from Cotes (10). Minute ventilation $\left(\mathrm{V}_{\mathrm{E}}\right)$, breathing frequency $(\mathrm{f})$, and tidal volume $\left(\mathrm{V}_{\mathrm{T}}\right)$ were also obtained on the same equipment. Restriction was defined as an FVC of $<80 \%$ of the predicted value and an FEV\% of $\geq 70 \%$. Obstruction was assumed when the $\mathrm{FEV}_{1.0}$ was $<80 \%$ of the predicted value and the FEV\% was $<70 \%$.

The single-breath diffusing lung capacity for carbon monoxide $\left(\mathrm{D}_{\mathrm{LCO}}\right)$ was measured with the subject seated (MASTERLAB ${ }^{\circledR}$, Jaeger, Germany), and the predicted values were derived from Cotes \& Hall (11). The average of the two acceptable tests was used. The measured $\mathrm{D}_{\mathrm{LCO}}$ values were consecutively corrected for carboxyhemoblobin (COHb), hemoglobin $(\mathrm{Hb})$, and partial pressure of oxygen in alveolar air $\left(\mathrm{PA}_{\mathrm{O} 2}\right)$ as follows:

$$
\begin{aligned}
\mathrm{D}_{\mathrm{LCOcourected}}= & \mathrm{D}_{\mathrm{LCOmeasured}} \cdot \mathrm{f}(\mathrm{COHb}) \\
& \cdot \mathrm{f}(\mathrm{Hb}) \cdot \mathrm{f}\left(\mathrm{PA}_{\mathrm{O} 2}\right)
\end{aligned}
$$

(equation 1)

where

$$
f(\mathrm{COHb})=1+\mathrm{COHb}(\%) / 100 \quad \text { (equation 1a) }
$$

is a factor to correct for $\mathrm{COHb}$ induced by $\mathrm{D}_{\mathrm{LCO}}$ measurement (12). We did not measure $\mathrm{COHb}$; instead we theoretically estimated an $0.7 \% \mathrm{COHb}$ rise per each test performed (13), while

$$
\begin{aligned}
f(H b)= & {\left[10.22+\mathrm{Hb}\left(\mathrm{g} \cdot \mathrm{dl}^{-1}\right)\right] } \\
& /\left[1.7 \cdot \mathrm{Hb}\left(\mathrm{g} \cdot \mathrm{dl}^{-1}\right)\right]
\end{aligned}
$$

adjusts $\mathrm{D}_{\mathrm{LCO}}$ to the normal $\mathrm{Hb}$ value of $14.6 \mathrm{~g} \cdot \mathrm{dl}^{-1}$ (12) and

$$
\begin{aligned}
& \mathrm{f}\left(\mathrm{PA}_{\mathrm{O} 2}\right)=(1.1 / \Theta) \cdot(1+1.43 \cdot \Theta) / 2.57 \quad \text { (equation 1c) } \\
& \Theta=0.006\left(\mathrm{PA}_{\mathrm{O} 2}(\mathrm{~mm} \mathrm{Hg})-10\right)+0.33
\end{aligned}
$$

adjusts $D_{L C O}$ to the normal $P_{A_{2}}$ value of $105 \mathrm{~mm}$ $\mathrm{Hg}(13.97 \mathrm{kPa})$. This correction originates from our previous report [14 (equations 13 and 14)] by adaptation to traditional units and adoption of the normal value for the ratio of the pulmonary capillary blood volume ( $\mathrm{Vc}$ ) and the membrane diffusing capacity $(\mathrm{Dm})$; that is, $\mathrm{Vc} / \mathrm{Dm}$ was assumed to be $1.43 \mathrm{ml}$ blood $\cdot \min \cdot \mathrm{mm} \mathrm{Hg} \cdot \mathrm{ml}^{-1} \mathrm{CO}$.

\begin{tabular}{|c|c|c|c|c|c|c|c|c|c|c|c|c|c|c|}
\hline \multirow{3}{*}{ Group } & \multicolumn{3}{|c|}{ Age (years) } & \multicolumn{5}{|c|}{ Smoking category } & \multicolumn{3}{|c|}{$\begin{array}{c}\text { Pack-years of cigarette } \\
\text { smoking }\end{array}$} & \multicolumn{3}{|c|}{ Exposure in fiber-years } \\
\hline & \multirow[t]{2}{*}{ Mean } & \multirow[t]{2}{*}{ SD } & \multirow[t]{2}{*}{ Range } & \multirow{2}{*}{$\begin{array}{l}\text { Non- } \\
\text { smoker } \\
\text { (N) }\end{array}$} & \multicolumn{2}{|c|}{ Ex-smoker } & \multicolumn{2}{|c|}{$\begin{array}{l}\text { Current } \\
\text { smoker }\end{array}$} & \multirow[t]{2}{*}{ Mean } & \multirow[t]{2}{*}{ SD } & \multirow[t]{2}{*}{ Range } & \multirow[t]{2}{*}{ Mean } & \multirow[t]{2}{*}{ SD } & \multirow[t]{2}{*}{ Range } \\
\hline & & & & & N & $\%$ & $N$ & $\%$ & & & & & & \\
\hline $\begin{array}{l}\text { Plaque } \\
(N=55)\end{array}$ & 58.2 & 10.1 & $46-66$ & 12 & 9 & 16 & 34 & 62 & 37.7 & 29.4 & $0-183$ & 39.6 & 12.3 & $28-78$ \\
\hline $\begin{array}{l}\text { No-plaque } \\
(\mathrm{N}=252)\end{array}$ & 50.8 & 12.0 & $23-63$ & 114 & 43 & 17 & 95 & 38 & 29.5 & 23.9 & $0-162$ & 31.2 & 17.8 & $2-73$ \\
\hline $\begin{array}{l}\text { Total } \\
(\mathrm{N}=307)\end{array}$ & 52.1 & 11.8 & $23-66$ & 126 & 52 & 17 & 129 & 42 & 31.4 & 25.3 & $0-183$ & 32.7 & 16.9 & $2-78$ \\
\hline
\end{tabular}

For all of the subjects arterial blood was sampled in duplicate via arterial lines placed in the radial artery. In order to avoid potential effects on ventilation from the insertion of arterial lines, samples were obtained about 20 min after insertion. Xylocain was

Table 1. Demographic and exposure characteristics of the plaque and no-plaque groups. 
used as the local anesthetic; the volumes of drawn blood ranged from $1.5-2 \mathrm{ml}$. The average values of the two measurements of $\mathrm{Pa}_{\mathrm{CO} 2}, \mathrm{~Pa}_{\mathrm{O} 2}$, and $\mathrm{pH}$ were adopted (ABL-1, Radiometer, Denmark). The machine used for the measurements had a built-in automatic calibrating set for periodic checks every $20 \mathrm{~min}$. Hypocapnia was assumed when the value of $\mathrm{Pa}_{\mathrm{CO} 2}$ was less than $35 \mathrm{~mm} \mathrm{Hg}(4.66 \mathrm{kPa})$, while the normocapnic range was defined as a $\mathrm{Pa}_{\mathrm{CO} 2}$ of 35 $45 \mathrm{~mm} \mathrm{Hg}(4.66-5.99 \mathrm{kPa})$. The subjects with plaques were not aware of their plaque status.

We emphasize that the no-plaque group should not be considered strictly as a reference group in the statistical sense, but rather as a comparative group of fellow workers from the same factory. Since the two groups were formed by the discriminative criterion of having pleural plaques proved to be different regarding many anthropometric and exposure parameters, besides simple univariate tests, the remaining associations between the presence of plaques and pulmonary function were examined by multivariate tests, potential confounders being controlled for.

The test results were expressed as means and standard deviations. For the univariate analyses the Mann-Whitney and chi-square tests were used to evaluate the significance of the differences in the pulmonary function tests, arterial blood gases, and prevalences of restriction and obstruction between the plaque and no-plaque groups. To evaluate the associations between pleural plaques and the various functional parameters that remained after control for the potential confounders of age, asbestos exposure, and smoking, a logistic regression was used. The relation between the quantitative pleural score (QPS) and the $\mathrm{Pa}_{\mathrm{CO} 2}$ was assessed by linear regression. A P-value of $<0.05$ was considered significant.

\section{Results}

For the workers with plaques the mean FVC was $75.8 \%$ of the predicted value, the mean $\mathrm{FEF}_{25-75 \%}$ was $88.2 \%$ of the predicted, the mean FEV\% was $114.7 \%$ of the predicted, and the mean total lung capacity was $89.3 \%$ of the predicted. All of these values were significantly different from those of the workers without plaques $\left(\mathrm{P}<10^{-6}, \mathrm{P}=0.0001, \mathrm{P}<10^{-6}\right.$, and $P=0.000002$, respectively) (table 2 ). Both the mean measured $\mathrm{D}_{\mathrm{LCO}}$ and corrected $\mathrm{D}_{\mathrm{LCO}}$ were significantly lower in the group with plaques than in the no-plaque group $\left(\mathrm{P}<10^{-6}\right.$ and $\mathrm{P}=0.003$, respectively) (table 2). Forty-two percent in the plaque group ( 23 of 55 workers) had restrictive disorder, compared with $16.7 \%$ of the no-plaque group (41 of 252 workers) $(P=0.00005)$. Thus the risk ratio for having a pulmonary restriction between the plaque and noplaque group can be assessed as 23:55/41:252 $=2.57$. As for the obstruction, the two groups did not differ significantly $(P=1.0)$ (table 2$)$.

For the workers with plaques the mean breathing frequency was 20.2 breaths $\cdot \mathrm{min}^{-1}$, a value which is 1.41 times greater than the 14.3 breaths $\cdot \mathrm{min}^{-1}$ of the no-plaque group $\left(\mathrm{P}<10^{-6}\right)$. Tidal volume $\left(\mathrm{V}_{\mathrm{T}}\right)$ was also larger in the plaque group $(\mathrm{P}=0.005)$. Consequently tidal volume, being the product of $f \cdot V_{T}$, was significantly larger in the group with plaques $\left(\mathrm{P}<10^{-6}\right)$. As a result of resting hyperventilation, $\mathrm{Pa}_{\mathrm{O}}$ and $\mathrm{pH}$ were increased, while $\mathrm{Pa}_{\mathrm{CO} 2}$ was decreased in the plaque group when compared with the noplaque group $\left(\mathrm{P}<10^{-6}\right.$, for each comparison), and hypocapnia was present more frequently in the subjects with plaques $\left(\mathrm{X}^{2}=232, \mathrm{P}<10^{-6}\right)$ (table 3$)$. Dyspnea was reported by $74 \%$ of the workers with plaques (41 of 55 workers), which was a much higher prevalence than in the no-plaque group ( $12 \%$ or 30 of 252 workers) $\left(\mathrm{X}^{2}=96.5, \mathrm{P}<10^{-6}\right)$.

In the logistic regression analysis, after control for age, pack-years of cigarette smoking, and fiber-years of asbestos exposure, the presence of hypocapnia $\left(\mathrm{P}<10^{-6}\right)$, decrements in FVC (\% predicted) $(\mathrm{P}=$ $0.03)$, and total lung capacity $(\%$ predicted $)(\mathrm{P}=$ 0.08 ), as well as the increment in the FEV\% (\% predicted) $(P=0.04)$, remained significantly associated with the presence of pleural plaques (table 4). Dec-

Table 2. Results of the pulmonary function tests of the plaque and no-plaque groups. (FVC $=$ forced vital capacity, $F E V_{1.0}=$ forced expiratory volume in $1 \mathrm{~s}, \mathrm{FEV} \%=\left(100 \cdot \mathrm{FEV}_{1.0}\right) / \mathrm{FVC}, \mathrm{FEF}_{25-75}=$ forced midexpiratory flow rate, TLC = total lung capacity, $\mathrm{RV}=$ residual volume, $\mathrm{D}_{\mathrm{LCO}}=$ diffusing lung capacity for carbon monoxide, $D_{\mathrm{LCO}}: V_{\mathrm{A}}=$ ratio of $\mathrm{D}_{\mathrm{LCO}}$ to alveolar volume, $\mathrm{CO}=$ carbon monoxide)

\begin{tabular}{|c|c|c|c|c|c|c|c|c|c|c|c|c|c|c|c|c|c|c|c|c|c|c|}
\hline \multirow{3}{*}{ Group } & \multicolumn{8}{|c|}{ Flow volume curve } & \multicolumn{2}{|c|}{ Restriction } & \multicolumn{2}{|c|}{ Obstruction } & \multicolumn{4}{|c|}{ Body plethysmography } & \multicolumn{6}{|c|}{ Single breath $\mathrm{CO}$ diffusion } \\
\hline & \multicolumn{2}{|c|}{$\begin{array}{l}\text { FVC } \\
(\% \text { a })\end{array}$} & \multicolumn{2}{|c|}{$\begin{array}{l}\mathrm{FEV}_{1.0} \\
(\% \mathrm{a})\end{array}$} & \multicolumn{2}{|c|}{$\begin{array}{c}\mathrm{FEV} \% \\
(\% \text { a) }\end{array}$} & \multicolumn{2}{|c|}{$\begin{array}{c}\mathrm{FEF}_{25-75} \\
\left(\%{ }^{\text {a }}\right)\end{array}$} & \multirow{2}{*}{$\mathrm{N}$} & \multirow{2}{*}{$\%$} & \multirow{2}{*}{$\mathrm{N}$} & \multirow{2}{*}{$\%$} & \multicolumn{2}{|c|}{$\begin{array}{l}\text { TLC } \\
(\% a) \\
\end{array}$} & \multicolumn{2}{|c|}{$\begin{array}{c}\text { RV } \\
(\% \text { a) }\end{array}$} & \multicolumn{2}{|c|}{$\begin{array}{l}\mathrm{D}_{\mathrm{LCO}} \\
(\% \mathrm{a})\end{array}$} & \multicolumn{2}{|c|}{$\begin{array}{c}D_{\text {LCo corrected }} \\
(\% \text { a) }\end{array}$} & \multicolumn{2}{|c|}{$\begin{array}{c}D_{L C O}: V_{A} \\
(\% a)\end{array}$} \\
\hline & Mean & SD & Mean & SD & Mean & SD & Mean & SD & & & & & Mean & SD & Mean & SD & Mean & SD & Mean & SD & Mean & SD \\
\hline $\begin{array}{l}\text { Plaque } \\
(\mathrm{N}=55)\end{array}$ & 75.8 & 12.7 & 86.8 & 10.6 & 114.5 & 9.7 & 88.2 & 15.2 & 23 & 41.9 & 4 & 7.2 & 89.3 & 10.8 & 91.9 & 12.8 & 89.9 & 11.6 & 90.6 & 11.8 & 95.5 & 15.8 \\
\hline $\begin{array}{l}\text { No.plaque } \\
(\mathrm{N}=252)\end{array}$ & 92.2 & 9.9 & 89.0 & 12.0 & 96.5 & 8.8 & 97.1 & 10.2 & 41 & 16.2 & 23 & 9.2 & 97.2 & 12.1 & 95.7 & 13.8 & 98.8 & 12.6 & 96.8 & 12.7 & 102.2 & 16.8 \\
\hline P.value & \multicolumn{2}{|c|}{$<10^{-6}$} & \multicolumn{2}{|c|}{0.14} & \multicolumn{2}{|c|}{$<10^{-6}$} & \multicolumn{2}{|c|}{0.0001} & \multicolumn{2}{|c|}{0.0002} & \multicolumn{2}{|c|}{1.0} & \multicolumn{2}{|c|}{0.00002} & \multicolumn{2}{|c|}{0.062} & \multicolumn{2}{|c|}{$<10^{-6}$} & \multicolumn{2}{|c|}{0.003} & \multicolumn{2}{|c|}{0.002} \\
\hline $\begin{array}{l}\text { Total } \\
(\mathrm{N}=307)\end{array}$ & 89.3 & 10.6 & 88.6 & 11.6 & 99.7 & 9.0 & 95.5 & 11.6 & 64 & 18.5 & 27 & 7.9 & 95.8 & 11.8 & 95.0 & 13.5 & 97.2 & 12.3 & 95.7 & 12.4 & 101.1 & 16.5 \\
\hline
\end{tabular}

a Percentage of the predicted value. 
Table 3. Ventilatory parameters and arterial blood gases of the plaque and no-plaque groups. $\left(\mathrm{Pa}_{\mathrm{O} 2}=\right.$ partial pressure of oxygen in arterial blood, $\mathrm{Pa}_{\mathrm{CO} 2}=$ partial pressure of carbon dioxide in arterial blood)

\begin{tabular}{|c|c|c|c|c|c|c|c|c|c|c|c|c|c|c|}
\hline \multirow{3}{*}{ Group } & \multicolumn{6}{|c|}{ Ventilatory parameters } & \multicolumn{6}{|c|}{ Arterial blood gases } & \multicolumn{2}{|c|}{ Hypocapnia $^{a}$} \\
\hline & \multicolumn{2}{|c|}{$\begin{array}{c}\text { Breathing } \\
\text { frequency } \\
\text { (breaths } \\
\text { min-1) }^{-1}\end{array}$} & \multicolumn{2}{|c|}{$\begin{array}{l}\text { Tidal volume } \\
\text { (I) }\end{array}$} & \multicolumn{2}{|c|}{$\begin{array}{c}\text { Minute } \\
\text { ventilation } \\
\left(1 \cdot \min ^{-1}\right)\end{array}$} & \multicolumn{2}{|c|}{$\begin{array}{c}\mathrm{Pa}_{\mathrm{O} 2} \\
(\mathrm{~mm} \mathrm{Hg})^{\mathrm{b}}\end{array}$} & \multicolumn{2}{|c|}{$\underset{(\mathrm{mm} \mathrm{Hg})^{\mathrm{b}}}{\mathrm{Pa}_{\mathrm{Co} 2}}$} & \multicolumn{2}{|c|}{$\mathrm{pH}$} & \multirow[t]{2}{*}{$\mathbf{N}$} & \multirow[t]{2}{*}{$\%$} \\
\hline & Mean & SD & Mean & SD & Mean & SD & Mean & SD & Mean & SD & Mean & SD & & \\
\hline $\begin{array}{l}\text { Plaque } \\
(\mathrm{N}=55)\end{array}$ & 20.2 & 2.5 & 0.43 & 0.08 & 8.5 & 1.1 & 99.7 & 14.3 & 32.7 & 1.5 & 7.42 & 0.03 & 44 & 80 \\
\hline $\begin{array}{l}\text { No-plaque } \\
(\mathrm{N}=252)\end{array}$ & 14.1 & 1.9 & 0.46 & 0.06 & 6.5 & 0.7 & 89.1 & 11.8 & 37.5 & 2.0 & 7.38 & 0.04 & - & 0 \\
\hline P-value & \multicolumn{2}{|c|}{$<10^{-6}$} & \multicolumn{2}{|c|}{0.005} & \multicolumn{2}{|c|}{$<10^{-6}$} & \multicolumn{2}{|c|}{$<10^{-6}$} & \multicolumn{2}{|c|}{$<10^{-6}$} & \multicolumn{2}{|c|}{$<10^{-6}$} & \multicolumn{2}{|c|}{$<10^{-6}$} \\
\hline Total $(\mathrm{N}=307)$ & 15.2 & 2.1 & 0.45 & 0.06 & 6.9 & 0.8 & 91.0 & 12.3 & 36.6 & 1.9 & 7.39 & 0.04 & 44 & 14 \\
\hline
\end{tabular}

a Defined as $\mathrm{Pa}_{\mathrm{CO} 2}$ of $<35 \mathrm{~mm} \mathrm{Hg}$.

b $1 \mathrm{~mm} \mathrm{Hg}=0.133 \mathrm{kPa}$.

Table 4. Association of pleural plaques with various parameters of pulmonary function after control for age, packyears of cigarette smoking, and fiber-years of asbestos exposure. (FVC $=$ forced vital capacity, $T L C=$ total lung capacity, $\mathrm{FEV}_{1.0}=$ forced expiratory volume in $1 \mathrm{~s}, \mathrm{FEV} \%=(100$ $\mathrm{FEV}_{10} / \mathrm{FVVC}, \mathrm{D}_{\mathrm{LCO}}=$ single-breath diffusing lung capacity for carbon monoxide, $D_{\text {Lco corrected }}=D_{\text {LCO }}$ values consecutively corrected for carboxyhemoglobin)

\begin{tabular}{lc}
\hline Parameter & $\begin{array}{c}\text { Significantly } \\
\text { associated with } \\
\text { pleural plaques }\end{array}$ \\
\hline Presence of hypocapnia & Yes \\
Increment in tidal volume & No \\
Increment in breathing frequency & Yes \\
Decrement in FVC & Yes \\
Decrement in TLC & Yes \\
Decrement in FEV & No \\
Increment in FEV\% & Yes \\
Decrement in $D_{\text {LCO }}$ & Yes \\
Decrement in $\mathrm{D}_{\text {LCO corrected }}$ & No \\
\hline
\end{tabular}

rements in the measured $\mathrm{D}_{\mathrm{LCO}}(\%$ of age, height, and gender predicted) and increments in the breathing frequency revealed a significant association with the presence of plaques, after control for smoking and exposure $(P=0.04$ and $P=0.00002$, respectively). However, $\mathrm{D}_{\text {Lcocorrected }}(\%$ of predicted) was not found to be significantly associated with plaques $(P=0.07)$ (table 4). The logarithm of QPS exhibited a stronger linear relation to $\mathrm{Pa}_{\mathrm{CO}}$ than did the QPS itself (correlation coefficient -0.70 versus -0.62 ) (figure 1 ).

\section{Discussion}

Exposure to asbestos can lead to a restrictive ventilatory disorder, a decrease in lung static compliance, and a reduction in lung diffusing capacity for carbon monoxide $(15,16)$. Recent longitudinal studies have reported transient increases in $\mathrm{D}_{\mathrm{LCO}}$ and $\mathrm{FEF}_{25-75 \%}$ as the earliest functional abnormalities, which are followed by normalization and ultimate

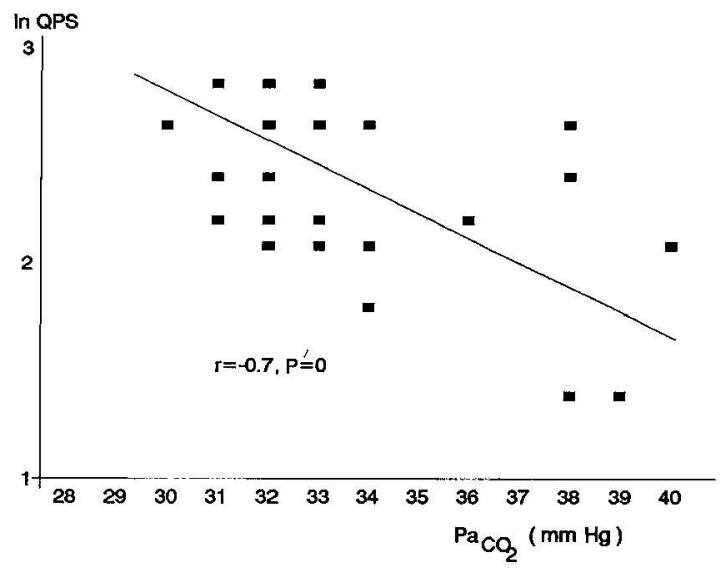

Figure 1. Relation between the logarithm of the quantitative pleural score (In QPS) and the partial pressure of carbon dioxide in arterial blood $\left(\mathrm{Pa}_{\mathrm{CO}}\right)$. $(1 \mathrm{~mm} \mathrm{Hg} \approx 0.133 \mathrm{kPa})$

reduction in some asbestos-exposed subjects $(17,18)$. This dynamics of pulmonary function indices may account for the large range of the values that are usually observed in cross-sectional studies, depending on the prevalence of the subjects in various stages of asbestosis. The few cross-sectional studies available had shown that some functional abnormalities can be present in subjects with normal chest radiographs $(19,20)$.

In the present study we observed a resting hyperventilation in $80 \%$ of the asbestos-exposed workers with radiographic evidence of pleural plaques. None of the control variables of age, smoking, or exposure entered significantly into the assessment of an association of plaques with resting hyperventilation. Previously, resting hyperventilation was found to be associated with asbestos exposure only in cases with progressive parenchymal and pleural fibrosis leading to arterial hypoxemia and increased chemical respiratory drive (5). A similar response was also reported for patients with chronic interstitial lung dis- 
ease $(6,21)$. Since our plaque group was normoxemic, chemical humoral factors can be ruled out as the cause; thus the possible mechanisms of resting hyperventilation are mechanical adaptation to the increased elastic work of breathing or a reflex-mediated increase in breathing frequency originating from the chest wall receptors (22). Quantitative support for the hypothesis that pleural plaques provoke resting hyperventilation is the observed significant linear correlation between the pleural score and $\mathrm{Pa}_{\mathrm{CO} 2}$ (correlation coefficient -0.70 ).

The analysis of the functional impairment observed in subjects with radiological pleural changes is becoming an important issue since a large number of workers with a low-to-moderate exposure history have asbestos-associated pleural disease $(23,24)$. The restrictive ventilatory disorder observed in $42 \%$ of our subjects with plaques was characterized by a reduction in FVC and an increase in the $\mathrm{FEV} \%$, since $\mathrm{FEV}_{1.0}$ was in the normal range. The variable smoking did not enter significantly into the logistic regression of plaque entity versus restriction entity, and this finding is physiologically plausible. Generally, smoking can be related to obstruction, but such a relation was not observed in this study. However, the variable exposure entered significantly into the multivariate analysis of plaque-restriction association. Therefore, a plausible conclusion can be drawn that pleural plaques and the associated restrictive disease were due to cumulative asbestos exposure. The mean $\mathrm{D}_{\mathrm{LCO}}$ (\% of predicted), whether corrected for $\mathrm{COHb}$ and adjusted to normal $\mathrm{Hb}$ and $\mathrm{Pa}_{\mathrm{O} 2}$ or not, in the plaque group was significantly lower than in the no-plaque group. However, after control for smoking and exposure, $\mathrm{D}_{\text {Lcocorrected }}(\%$ of predicted) proved to have a less than significant association with plaques. This finding suggests that plaques and $\mathrm{D}_{\mathrm{LCO}}$ deterioration are relatively independent entities, but it also indicates the possibility that, in the workers with plaques, the $\mathrm{D}_{\mathrm{LCO}}$ decrease could have been an early sign of coexisting interstitial lung disease. However, mild $\mathrm{D}_{\mathrm{LCO}}$ reduction in our subjects with plaques was not responsible for the resting hyperventilation, as was evident from their increased $\mathrm{Pa}_{\mathrm{O} 2}$, which proved that the alveocapillary membrane was not an obstacle to gas exchange. Measuring the $\mathrm{D}_{\mathrm{LCO}}$ components membrane diffusing capacity and capillary blood volume might prove useful in gaining some insight into the mechanisms involved. Oliver et al $(2,3)$ reported restrictive functional impairments in railroad workers, a finding which is in accord with our results, except for $\mathrm{D}_{\mathrm{L}, \mathrm{CO}}$, which was less affected in their sample. In addition our study included arterial gas determinations and revealed a strikingly high prevalence of hypocapnia in the asbestos-exposed workers with plaques.

As for the potential shortcomings of the study, there is a lack of computed tomography results to help exclude early parenchymal disease. As already mentioned, this lack should not invalidate the as- sessed association between plaques and hyperventilation, but its correction might lead to some insight into the association between plaques and restriction. Another problem is that exposure in the 1950s was only estimated and not measured and that some crocidolite was used until 1964. If, in consequence, the exposure of the older plaque workers was underestimated, the estimate of the association between plaques and resting hyperventilation would not be affected, but the estimate of the plaque-restriction association would.

In conclusion, resting hyperventilation was observed in a significant portion of our asbestos-exposed subjects and was related to pleural plaques. The pleural plaques themselves appeared to be related to restrictive impairments.

\section{References}

1. McGavin CR, Sheers G. Diffuse pleural thickening in asbestos workers: disability and lung function abnormalities. Thorax 1984;39:604-7.

2. Oliver LC, Eisen EA, Grene R, Sprince NL. Asbestos-related disease in railroad workers. Am Rev Respir Dis 1985;131:499-504.

3. Oliver LC, Eisen EA, Greene R, Sprince NL. Asbestos-related pleural plaques and lung function. Am J Ind Med 1988;14:649-56.

4. Schwartz DA. New development in asbestos-induced pleural disease. Chest 1991;99:191-8.

5. Gernez-Rieux C, Marchand M, Mountier-Kuhn P, Policard A, Roche L. Broncho-pneumopathies professionnelles. Paris: Masson, 1961.

6. Renzi GD, Lopez-Majano V. Early diagnosis of interstitial fibrosis. Respiration 1976;33:294-302.

7. Ferris BG. Epidemiology standardization project. Am Rev Respir Dis 1978;118:1-87.

8. International Labour Office (ILO). Guidelines for the use of ILO international classification of radiographs of pneumoconioses. Geneva: ILO, 1980. (Occupational safety and health series; no 22.)

9. Gardner RM. Standardization of spirometry - 1987 update. Am Rev Respir Dis 1987;136:1285-98.

10. Cotes JE. Lung function at different stages of life, including reference values. In: Cotes JE, ed. Lung function, 3rd ed. London: Oxford Blackwell Scientific Publications, 1975:340-95.

11. Cotes JE, Hall AM. The transfer factor for the lung; normal values in adults. In: Arcangeli P, ed. Normal values for respiratory function in man. Torino: Panminerva Medica, 1970:327-43.

12. Cotes JE. Measurement of the transfer factor for the lung and its subdivisions. In: Cotes JE, ed. Lung function, 3rd ed. London: Oxford Blackwell Scientific Publications, 1975:249.

13. Fahey PJ, Utell MJ, Condemi JJ, Green R, Hyde RW. Raynaud's phenomenon of the lung. Am J Med 1984; 76:263-9.

14. Dujic Z, Eterovic D, Denoble P, Krstacic G, Tocilj J. Diffusing lung capacity in hyperbaric environment: assessment by rebreathing technique. $\mathrm{Br} \mathrm{J}$ Ind Med 1992;49:254-9.

15. Becklake MR. Asbestos-related diseases of the lung and other organs: their epidemiology and complications for clinical practice. Am Rev Respir Dis 1976; 114:187-271.

16. Fournier-Massey G, Becklake MR. Pulmonary function profiles in Quebec asbestos workers. Bull Physiopathol Respir 1975;11:429—45. 
17. Dujic Z, Tocilj J, Saric M. Early detection of interstitial lung disease in asbestos-exposed nonsmoking workers by mid-expiratory flow rate and high-resolution CT changes. Br J Ind Med 1991;48:663-4.

18. Dujic Z, Tocilj J, Boschi S, Saric M, Eterovic D. Biphasic diffusing lung capacity: detection of early asbestos-induced lung functional changes. $\mathrm{Br} \mathrm{J}$ Ind Med 1992;49:260-7.

19. Rosenstock L, Barnhart S, Heyer NJ, Pierson DJ, Hudson LD. Relation among pulmonary function, chest roentgenographic abnormalities, and smoking status in an asbestos-exposed cohort. Am Rev Respir Dis 1988; 138:272-7.

20. Tocilj J, Dujic Z, Boschi S, Saric M. Correlation of radiological and functional findings in workers exposed to chrysotile asbestos. Med Lav 1990;81:37381.
21. Laurenco RV, Turino GM, Davidson LAG, Fishman AP. The regulation of ventilation in diffuse pulmonary fibrosis. Am J Med 1965;38:198-216.

22. Remmers JD, Martilla I. Action of intercostal muscles afferents on the respiratory rhythm of anesthetized cats. Respir Physiol 1974;24:31-41.

23. Baker EL, Dagg T, Greene RE. The significance of asbestos - associated pleural disease among sheet metal workers. J Occup Med 1985;27:483-9.

24. Sprince NL, Oliver CL, McLoud TC. Asbestos-related disease in plumbers and pipefitters employed in building construction. J Occup Med 1985;27: $771-5$.

Received for publication: 30 December 1992 